\title{
ANALISIS USER EXPERIENCE UNTUK VIRTUAL GALLERY 3D MENGGABUNGKAN PANORAMA FOTO SEBAGAI MEDIA INFORMASI CANDI HINDU BUDHA
}

\author{
Ayung Candra Padmasari \\ Program Studi Pendidikan Multimedia, UPI Kampus Cibiru \\ Universitas Pendidikan Indonesia \\ Jl. Pendidikan No.15, Cibiru Wetan, Cileunyi, Bandung, Jawa Barat. \\ ayungcandra@upi.edu
}

\begin{abstract}
Abstrak
Teknologi realitas maya dan dunia virtual menjadi salah satu perkembangan teknologi yang terus dikembangkan sebagai media untuk menyampakan informasi maupun konten dalam bentuk digital. Kebutuhan akan media yang inovatif di era revolusi Industri 4.0 menjadi keharusan dan tantangan baru terutama melihat potensi budaya dan sejarahnya yang harus tetap dilestarikan seiring dengan perkembangan zaman dan teknologi. Salah satu topik yang menjadi tantangan dalam inovasi media saat ini adalah model media informasi yang sebelumnya di desain konvensional dalam menampilkan informasi terutama bidang sejarah, baik itu keilmuan murni maupun sejarah untuk media pembelajaran. Informasi sejarah candi Hindu Budha pada dasarnya merupakan sejarah yang sangat menarik dan wajib diketahui oleh semua orang, baik bagi anak anak, remaja maupun masyarakat umum. Penelitian ini berfokus pada perancangan user experience $(U X)$ untuk virtual galeri 3D menggabungkan panorama foto sebagai media informasi Candi Hindu budha di Jawa Barat berdasarkan pada kemudahan, efisiensi, dan kegunaan untuk pengguna. Metode dalam penelitian ini adalah Desain and Development ( $\mathrm{DnD})$. Penelitian dilakukan dengan menggunakan kuesioner sebagai instrumen penelitian. Kuesioner penelitian yang disebar terdiri atas 15 pertanyaan yang dikelompokkan menjadi lima variabel usability. Berdasarkan pengolahan data diperoleh hasil bahwa dari 5 variabel usability yang digunakan pada kuesioner, hanya 1 variabel yang signifikan digunakan untuk menganalisis usability aplikasi yaitu memorability. Dari 5 variabel tersebut aplikasi virtual gallery 3D memenuhi 4 variabel lainnya sehingga dapat disimpulkan bahwa aplikasi
\end{abstract}

android belum memenuhi kriteria-kriteria Usability, Learnability 85,6 \%, System Performance 76,9 \%, Eficiency 79,9\%, Memorability 74,2 \%, Satisfaction $85,04 \%$.

Kata kunci :

User Experience, Virtual Gallery, Virtual 3D, Panorama Foto.

\begin{abstract}
Virtual reality technology and virtual worlds are one of the technological developments that continue to be developed as a medium for conveying information and content in digital form. The need for innovative media in the era of the Industrial revolution 4.0 is a new necessity and challenge, especially seeing its cultural and historical potential which must be preserved along with the times and technology. One of the topics that is a challenge in media innovation today is the model of information media that was previously designed conventionally in displaying information, especially in the field of history, both pure science and history for learning media. Information on the history of Hindu-Buddhist temples is basically a very interesting history and must be known by everyone, both for children, teenagers and the general public. This study focuses on designing a user experience (UX) for a $3 D$ virtual gallery combining photo panoramas as a medium of information for HinduBuddhist temples in West Java based on ease, efficiency, and usability to use. The method in this research is Design and Development (DnD). The research was conducted using a questionnaire as a research instrument. The research questionnaire distributed consisted of 15 questions which were divided into five usability variables. processing Based on the data obtained, the results showed that of the 5
\end{abstract}


usability variables used in the questionnaire, only 1 significant variable was used to analyze the usefulness of the application, namely memorability. Of the 5 variables, the $3 D$ virtual gallery application meets 4 other variables so that it can be ascertained that the Android application does not meet the usability criteria, Learning Ability 85.6\%, System Performance $76.9 \%$, Efficiency $79.9 \%$, Memory 74.2 $\%$, Satisfaction $85.04 \%$.

Keywords :

User Experience, Virtual Gallery, Virtual 3D, Photo Panorama.

\section{Pendahuluan}

Kebutuhan akan media yang inovatif di era revolusi Industri 4.0 menjadi keharusan dan tantangan baru terutama melihat potensi budaya dan sejarahnya yang harus tetap dilestarikan seiring dengan perkembangan zaman dan teknologi. Salah satu topik yang menjadi tantangan adalah model media informasi yang sebelumnya di desain konvensional dalam menampilkan informasi terutama bidang sejarah, baik itu keilmuan murni maupun sejarah untuk media pembelajaran. Pengetahuan candi Hindu Budha pada dasarnya merupakan pengetahuan yang sangat menarik dan wajib diketahui oleh semua orang, baik anak anak remaja maupun masyarakat umum, karena sejarah Candi Hindu Budha termasuk bangunan suci peninggalan masa klasik Indonesia yang digunakan sebagai tempat pemujaan oleh umat beragama Hindu maupun Budha. Sejarah sebuah candi di Indonesia tidak terlepas dari sejarah sebuah kerajaan, karena pembangunan candi pada masa lalu adalah atas perintah seorang raja atau kepala pemerintahan yang menguasai wilayah tempat candi tersebut berada. Berabad-abad lamanya, sejak masa penjajahan Belanda, hampir tidak ada bangunan peninggalan kuno yang ditemukan di Jawa Barat. Peninggalan masa lalu yang dijadikan pijakan dalam upaya menjelaskan secara runtut sejarah kerajaankerajaan di Jawa Barat, khususnya kerajaan Hindu dan Buddha, selama ini berupa prasasti yang ditemukan di beberapa tempat serta kitab-kitab kuno, seperti Pustaka Jawadwipa, Pustaka Rajyarajya Bhumi Nusantara, dan Chu-fan-chi karangan Chau Ju-kua (1178-1225) yang merupakan catatan (buku) Cina yang memuat uraian tentang Sunda. (Perpusnas 2019). Meskipun Jawa Barat tercatat sebagai wilayah di Indonesia yang memiliki candi lumayan banyak, namun umumnya masyarakat di Jawa Barat tidak terlalu memperhatikan atau bahkan kurang menjaga peninggalan bersejarah.

Beberapa bangunan candi di provinsi Jawa Barat dijadikan oleh pemerintah sebagai objek destinasi wisata. Sebagian lagi banyak bangunan candi yang sudah banyak tergerus oleh arus perubahan jaman yang semakin modern. Berikut adalah daftar namanama candi di provinsi Jawa Barat : Candi Bojong Menje (Rancaekek), Candi Cangkuang (Garut), Candi Jiwa (Karawang), Percandian Batujaya (Kampung Talun), Candi Blandongan (Kampung Gunteng), Candi Tanggulun (Cianjur), Candi Serut (Karawang), Candi Sumur (Segaran IX), Candi Batu Kalde (Pangandaran).

\section{LANDASAN TEORI}

\section{II.1 Kajian Usability}

Kajian tentang usability (kegunaan) dalam pengukuran usability sistem menggunakan use questionnaire pada aplikasi android merupakan bagian dari bidang ilmu multi disiplin human computer interaction (HCI). Disampaikan oleh Nugroho (2009:2) Human Computer Interaction merupakan bidang ilmu yang berkembang sejak tahun 1970 yang mempelajari bagaimana mendesain tampilan layar komputer dalam suatu aplikasi sistem informasi agar nyaman dipergunakan oleh pengguna. Usability berasal dari kata usable yang secara umum berarti dapat digunakan dengan baik [1]. Sesuatu dapat dikatakan berguna dengan baik apalagi kegagalan dalam penggunaanya dapat dihilangkan atau diminimalkan serta memberi manfaat dan kepuasan kepada pengguna (Rubin dan Chisnell, 2008) dalam Joana (2010). Dalam ISO 9241:11 (1998) Usability didefinisikan dengan sejauh mana suatu produk dapat digunakan oleh pengguna tertentu untuk mencapai target yang ditetapkan dengan efektivitas, efesiensi dan mencapai kepuasan penggunaan dalam konteks tertentu [2]. Konteks penggunaan terdiri dari pengguna, tugas, peralatan (hardware, software dan material). Berdasarkan definisi tersebut usability diukur berdasarkan komponen :

1. Kemudahan (learnability) didefinisikan seberapa cepat pengguna mahir dalam menggunakan sistem serta kemudahan dalam penggunaan menjalankan suatu fungsi serta apa yang pengguna inginkan dapat meraka dapatkan. 
2. Efisiensi (efficiency) didefenisikan sebagai sumber daya yang dikeluarkan guna mencapai ketepatan dan kelengkapan tujuan.

3. Mudah diingat (memorability) didefinisikan bagaimana kemapuan pengguna mempertahankan pengetahuannya setelah jangka waktu tertentu, kemampuan mengingat didapatkan dari peletakkan menu yang selalu tetap.

4. Kesalahan dan keamanan (errors) didefinisikan berapa banyak kesalahan-kesalahan apa saja yang dibuat pengguna, kesalahan yang dibuat pengguna mencangkup ketidaksesuaian apa yang pengguna pikirkan dengan apa yang sebenarnya disajikan oleh sistem.

5. Kepuasan (satisfaction) didefinisikan kebebasan dari ketidaknyamanan, dan sikap positif terhadap penggunaan produk atau ukuran subjektif sebagaimana pengguna merasa tentang penggunaan sistem.

\section{II.2 Virtual Gallery 3D}

Gallery merupakan istilah yang berasal dari bahasa Inggris yang berarti tempat untuk memajang atau memamerkan sebuah karya seni. Fungsi dari galeri terutama untuk galeri batik adalah sebagai media dan tempat menyimpan dan menunjukkan karya batik kepada masyarakat umum dan sebagai media untuk mempromosikan karya tersebut.

Gallery adalah pameran dimana pameran merupakan kegiatan untuk memperkenalkan produk, karya atau gagasan kepada khalayak ramai. Misalnya pameran buku, tulisan, lukisan dan sebagainya [3].

Sedangkan fungsi galeri adalah sebagai wadah komunikasi antara konsumen dengan produsen. Pihak produsen yang dimaksud adalah para seniman sedangkan konsumen adalah kolektor dan masyarakat. Fungsi galeri adalah sebagai berikut :

1. Sebagai wadah promosi barang-barang seni.

2. Sebagai wadah pembinaan dan pengarahan bagi para seniman dalam mengembangkan dan memasarkan hasil karyanya.

3. Sebagai sarana komunikasi antara pengelola dan pengunjung dalam suasana yang rekreatif. Salah satu faktor penting dalam fasilitas galeri adalah membangkitkan suasana dan ritme yang baik. Berdasarkan studi banding hal tersebut dapat dicapai melalui perbedaan luasan ruang, desain interior yang menarik.

\section{II.3 Teknik Panorama Dalam Fotografi}

Panorama adalah salah satu istilah yang dipergunakan untuk sebuah visualisasi pandangan secara 360 derajat. Istilah ini dipergunakan oleh seorang seniman bernama Robert Barker pada tahun 1787 dalam karyanya yang berjudul "Apparatus for Exhibiting Pictures”. Istilah ini dimunculkan pertama kali dalam dunia cetak melalui artikel yang dimuat di The Morning Chronicle, sebuah penerbitan dari Inggris. Salah satu karyanya adalah Panorama of London Barker yang tampil berikut ini.

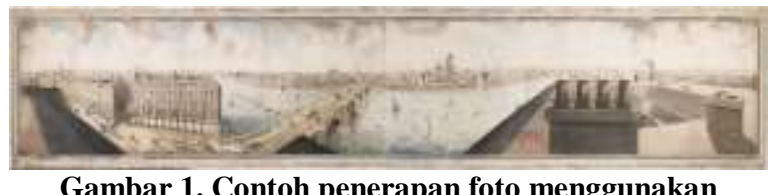

Gambar 1. Contoh penerapan foto menggunakan panorama.

Di dunia fotografi sendiri berbagai fotografer berupaya untuk menggabungkan beberapa foto yang mereka ambil menjadi sebuah foto Panorama. Upaya ini bahkan telah muncul sejak tahun 1800 -an. Namun kehadiran teknologi fotografi digital yang membuat foto Panorama semakin popular dan banyak dimanfaatkan oleh masyarakat. Dengan menggunakan teknologi digital, proses penggabungan foto yang disebut dengan proses image stitching menjadi semakin mudah.

\section{II.4 Candi Hindu Budha di Jawa Barat}

Sejarah sebuah candi di Indonesia tidak terlepas dari sejarah sebuah kerajaan, karena pembangunan candi pada masa lalu adalah atas perintah seorang raja atau kepala pemerintahan yang menguasai wilayah tempat candi tersebut berada. Berabad-abad lamanya, sejak masa penjajahan Belanda, hampir tidak ada bangunan peninggalan kuno yang ditemukan di Jawa Barat. Peninggalan masa lalu yang dijadikan pijakan dalam upaya menjelaskan secara runtut sejarah kerajaan-kerajaan di Jawa Barat, khususnya kerajaan Hindu dan Buddha, selama ini berupa prasasti yang ditemukan di beberapa tempat serta kitab-kitab kuno, seperti Pustaka Jawadwipa, Pustaka Rajyarajya Bhumi Nusantara, dan Chu-fan-chi karangan Chau Ju-kua (1178-1225) yang merupakan catatan (buku) Cina yang memuat uraian tentang Sunda. (Perpusnas 2019). Meskipun Jawa Barat tercatat sebagai wilayah di Indonesia yang memiliki candi lumayan banyak, namun umumnya masyarakat di Jawa Barat tidak 
terlalu memperhatikan atau bahkan kurang menjaga peninggalan bersejarah.

Beberapa bangunan candi di provinsi Jawa Barat dijadikan oleh pemerintah sebagai objek destinasi wisata. Sebagian lagi banyak bangunan candi yang sudah banyak tergerus oleh arus perubahan jaman yang semakin modern. Berikut adalah daftar namanama candi di provinsi Jawa Barat :

1. Candi Bojong Menje (Rancaekek),

2. Candi Cangkuang (Garut),

3. Candi Jiwa (Karawang),

4. Percandian Batujaya (Kampung Talun),

5. Candi Blandongan (Kampung Gunteng),

6. Candi Tanggulun (Cianjur),

7. Candi Serut (Karawang),

8. Candi Sumur (Segaran IX),

9. Candi Batu Kalde (Pangandaran).

berikut tampilan media interaktif virtual galeri 3D

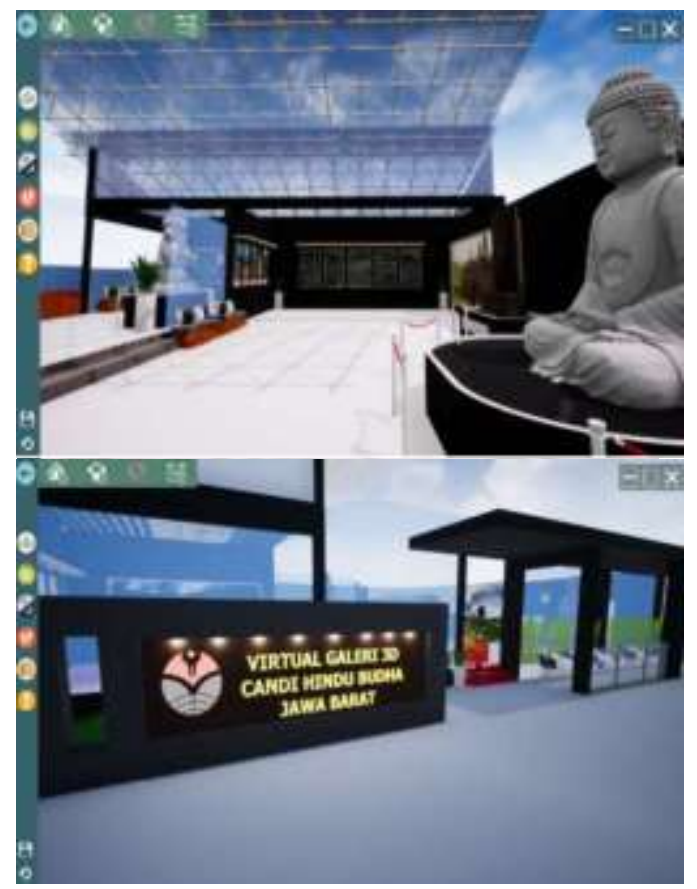

Gambar 2. Tampilan depan aplikasi Virtual galeri 3D menggunakan simlabVR

\section{Metodologi Penelitian}

\section{III.1 Ruang Lingkup Penelitian}

Sasaran responden sebagai pengguna adalah mahasiwa Program Studi Pendidikan Multimedia Kampus UPI di Cibiru yang berjumlah 50 responden dan Prototipe dikembangkan sampai dengan tingkat medium fidelity.

\section{III.2 Data Penelitian}

Metode pengumpulan data primer dilakukan dengan metode penyebaran angket atau kuesioner melalui media survei untuk mendapatkan data. Skala Likert dirancang untuk meyakinkan responden menjawab dalam berbagai tingkatan pada setiap butir pertanyaan atau pernyataan yang terdapat dalam kuesioner. Data tentang dimensi dari variabel-variabel yang dianalisis dalam penelitian ini yang ditujukan kepada responden menggunakan skala 1 sampai dengan 5 untuk mendapatkan data yang bersifat ordinal dan diberi skor sebagai berikut :

Tabel 1. Nilai setiap variabel.

\begin{tabular}{|l|l|l|l|l|l|}
\hline PK & $\begin{array}{l}\text { Sangat } \\
\text { baik }\end{array}$ & Baik & $\begin{array}{l}\text { Cukup } \\
\text { baik }\end{array}$ & $\begin{array}{l}\text { Kurang } \\
\text { baik }\end{array}$ & Buruk \\
\hline Nilai & 5 & 4 & 3 & 2 & 1 \\
\hline
\end{tabular}

Keterangan : PK = Pertanyaan

\section{III.3 Tahap Penelitian}

Tahap-tahap penelitian dideskripsikan dalam bentuk flowchart sebagai berikut :

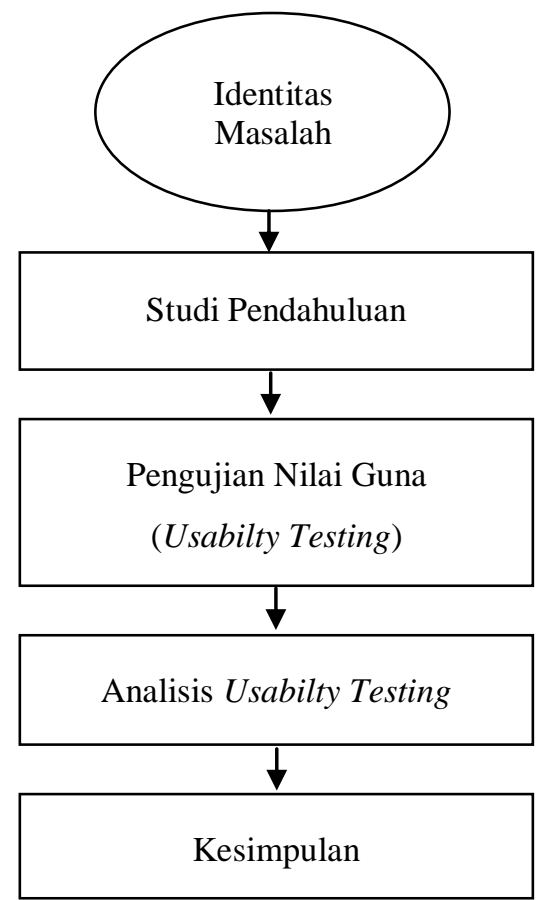

Gambar 2. Flowchart tahap-tahap penelitian.

Langkah awal usability testing ini adalah memberikan sejumlah task atau tugas yang sudah
Ayung Candra Padmasari

Jurnal Ilmiah Teknologi Informasi Terapan

Volume 8, No 1, 15 Desember 2021 
dipersiapkan sebelumnya kepada pengguna saat berinteraksi dengan sistem yang diuji. Tugas ini diberikan kepada 50 responden yang berasal dari mahasiswa. Tugas ini digunakan sebagai sarana interaksi dalam pengukuran usability (Sastramihardja dkk, 2008, Pengukuran usability dengan sarana task model dalam user center software development).

Tabel 2. Variabel untuk uji media.

\begin{tabular}{|c|c|}
\hline No & Pernyataan \\
\hline \multicolumn{2}{|c|}{ Learnability } \\
\hline 1 & $\begin{array}{l}\text { Control user untuk rotasi atau berbelok arah } \\
\text { galeri virtual dapat berfungsi dengan baik } \\
\text { dan mudah digunakan }\end{array}$ \\
\hline 2 & $\begin{array}{l}\text { Control user untuk berhenti berjalan } \\
\text { (berjelajah) dalam galeri virtual dapat } \\
\text { berfungsi dengan baik }\end{array}$ \\
\hline \multicolumn{2}{|c|}{ System Performance } \\
\hline 3 & $\begin{array}{l}\text { Selama menggunakan aplikasi, tidak } \\
\text { ditemukan } \text { bug, hang, atau error }\end{array}$ \\
\hline 4 & Main mепи keluar dapat berjalan \\
\hline 5 & $\begin{array}{l}\text { Program Keyboard untuk kontrol navigasi } \\
\text { dapat berjalan dengan baik (tidak bug atau } \\
\text { error) }\end{array}$ \\
\hline \multicolumn{2}{|c|}{ Efficiency } \\
\hline 6 & $\begin{array}{l}\text { Tidak ditemukan delay untuk controlling } \\
\text { menggunakan keyboard untuk berjalan } \\
\text { dalam Virtual Gallery }\end{array}$ \\
\hline 7 & $\begin{array}{l}\text { Tidak ditemukan delay graphic visual dalam } \\
\text { Virtual Gallery }\end{array}$ \\
\hline 8 & $\begin{array}{l}\text { Pengguna dapat dengan mudah } \\
\text { menggunakan controlling dengan keyboard } \\
\text { untuk berbelok arah dalam virtual gallery }\end{array}$ \\
\hline 9 & $\begin{array}{l}\text { Pengguna mampu melihat visualisasi Foto } \\
\text { Candi Hindu Budha di Jawa barat dengan } \\
\text { jelas }\end{array}$ \\
\hline \multicolumn{2}{|c|}{ Memorability } \\
\hline 10 & $\begin{array}{l}\text { Main menu dalam tampilan virtual gallery } \\
\text { mudah ditemukan }\end{array}$ \\
\hline 11 & $\begin{array}{l}\text { Menu masuk dan keluar mudah ditemukan } \\
\text { dan tidak berubah }\end{array}$ \\
\hline \multicolumn{2}{|c|}{ Satisfaction } \\
\hline 12 & $\begin{array}{l}\text { Warna yang ditampilkan nyaman dan tidak } \\
\text { mengganggu }\end{array}$ \\
\hline 13 & $\begin{array}{l}\text { Tata letak ruang dan proporsi sesuai dan } \\
\text { tidak mengganggu }\end{array}$ \\
\hline 14 & Desain interior 3D untuk galeri menarik \\
\hline 15 & $\begin{array}{l}\text { Panorama foto yang ditampilkan dapat } \\
\text { terlihat dengan mudah }\end{array}$ \\
\hline 16 & $\begin{array}{l}\text { Pemodelan untuk visualisasi asset } 3 D \text { dan } \\
\text { property dalam galeri sesuai dengan tema }\end{array}$ \\
\hline
\end{tabular}

Setelah pengguna menyelesaikan semua tugas yang ada, langkah selanjutnya adalah membagikan kuisioner kepada dosen, staff karyawan, dan mahasiswa yang berisi 15 pertanyaan yang sudah mewakili kelima aspek usability. Pengguna mengisi kuisioner yang sudah dibagikan berdasarkan pengalamannya (apa yang dilihat dan dirasakan) pada saat melakukan task atau tugas-tugas tadi. Tiap-tiap pertanyaan dari kuisioner tersebut bertujuan untuk menunjukkan tingkat usability menurut penerimaan user, yang akan dinilai dalam skala nilai 5 (Wingnjosoebroto dkk., 2009, Perancangan interface prototype web berdasarkan pada aspek usability). Berbagai pertanyaan yang diberikan dalam kuisioner ini dapat dilihat pada tabel 2.

Menurut Jacob Nielson, aspek-aspek dalam usability testing ini mencakup lima hal, yaitu :

1. Learnability, menjelaskan tingkat kemudahan pengguna atau user untuk menyelesaikan task-task dasar ketika pertama kali mereka melihat atau berhadapan dengan sistem yang ada.

2. Efficiency, menjelaskan seberapa cepat pengguna dapat menyelesaikan tugas-tugas yang ada saat mereka pertama kali mempelajari sistem tersebut.

3. Memorability, menjelaskan tetang tingkat kemudahan pengguna atau user dalam menggunakan sistem dengan baik, setelah beberapa lama tidak menggunakannya.

4. Errors, menjelaskan kemungkinan terjadinya error atau kesalahan yang dilakukan oleh pengguna dan seberapa mudah mereka dapat mengatasinya.

5. Satisfaction, menjelaskan tentang tingkat kepuasan pengguna dalam menggunakan sistem yang telah dibuat. Hasil plot kelima aspek usability di atas terhadap 15 pertanyaan kuisioner dapat dilihat pada Tabel 2.

Spesifikasi Komputer yang dibutuhkan dalam uji kelayakan media ini adalah Intel Core i5, 2,7 Ghz, dengan memory minimal $4 G B$ dan NVIDIA GTX 950 $2 G B$. Metode pengumpulan data primer dilakukan dengan metode penyebaran angket atau kuesioner melalui media survei untuk mendapatkan data. Menurut Sugiyono (1999) Skala Likert digunakan untuk mengukur sikap, pendapat, dan persepsi seseorang atau sekelompok orang tentang fenomena sosial yang merupakan skala kontinum bipolar, pada ujung sebelah kanan (angka rendah) menggambarkan suatu jawaban yang bersifat negative. Sedang ujung sebelah kiri (angka tinggi), menggambarkan suatu jawaban yang bersifat positif. Skala Likert dirancang 
untuk meyakinkan responden menjawab dalam berbagai tingkatan pada setiap butir pertanyaan atau pernyataan yang terdapat dalam kuesioner. Data tentang dimensi dari variabel-variabel yang dianalisis dalam penelitian ini yang ditujukan kepada responden menggunakan skala 1 sampai dengan 5 untuk mendapatkan data yang bersifat ordinal dan diberi skor sebagai berikut :

Data responden diambil dari data mahasiswa semester 3 program studi pendidikan Multimedia, Angkatan 2018, data nama responden dan hasil nya dijabarkan dalam tabel sebagai berikut :

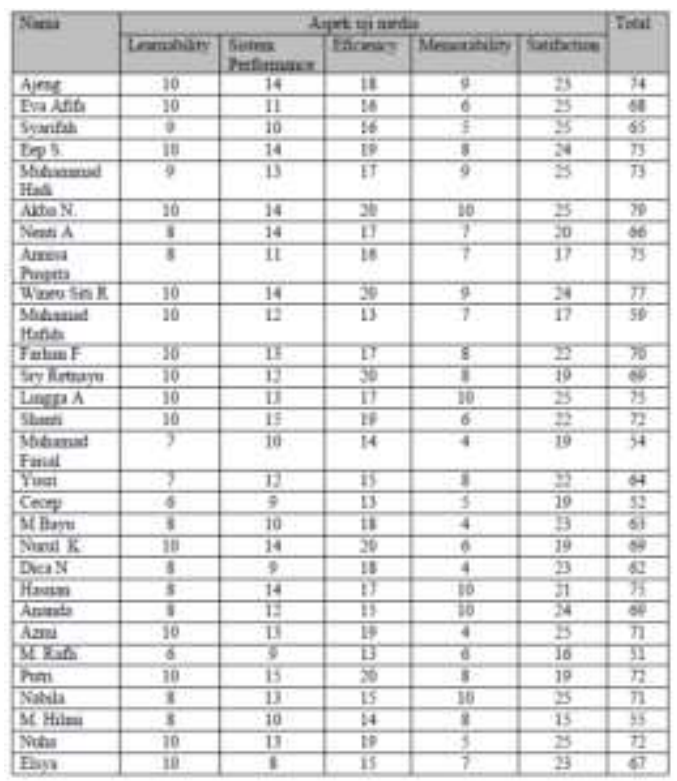

Tabel 3. Hasil perhitungan data responden.

\begin{tabular}{|l|r|r|r|r|r|r|}
\hline $\begin{array}{l}\text { Hasil } \\
\text { perhitungan }\end{array}$ & Learnability & $\begin{array}{l}\text { Sistem } \\
\text { Performance }\end{array}$ & Eficiency & Memorability & Satifaction & Total \\
\cline { 1 - 6 } $\begin{array}{l}\text { Skor Yang } \\
\text { Diperoleh }\end{array}$ & 428 & 577 & 799 & 371 & 1063 & 3268 \\
\cline { 1 - 5 } Skor maksimal & 500 & 750 & 1000 & 500 & 1250 & 4000 \\
\cline { 1 - 5 } & 85,6 & 76,93333 & 79,9 & 74,2 & 85,04 & \\
\hline
\end{tabular}

Persentase keseluruhan $=\frac{\text { Jumlah skor } \text { yang didapat }}{\text { jumiah skor maksimal }} \times 100 \%$

Persentase keseluruhan $=\frac{3268}{4000} \times 100 \%=81,7 \%$

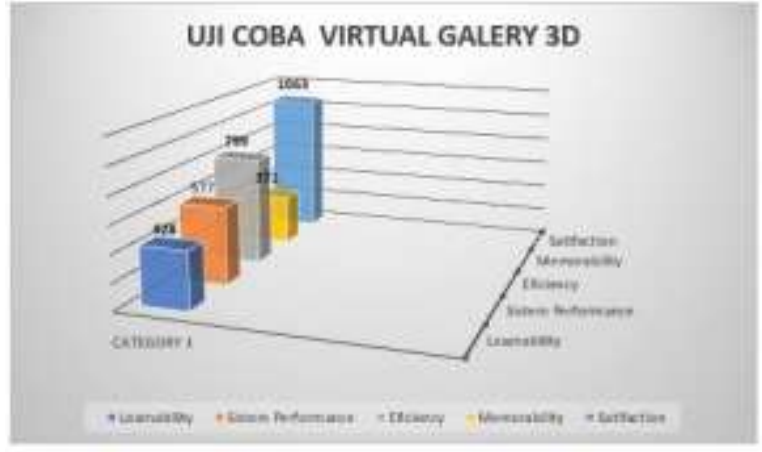

Gambar 3. Grafik Hasil Uji Coba Media.

Berdasarkan Grafik diatas, maka dapat disimpulkan dari Aspek Learnability, Aspek System Performance, Aspek Efiency, Aspek Memorability dan Aspek Satisfaction yang diambil dari data kuisoner Mahasiswa UPI Program Studi Pendidikan Multimedia dijabarkan sebagai berikut :

1. Dalam aspek Learnability menyatakan aplikasi Virtual Gallery 3D ini dengan nilai 85,6 \% "sangat baik" digunakan untuk memberikan informasi terkait candi-candi Hindu Budha yang ada di Jawa Barat, dengan dilihat dari penggunaan media yang mudah digunakan.

2. Dalam aspek Performance dari data yang diperoleh dapat disimpulkan bahwa Virtual Gallery 3D ini pun "baik" dengan hasil nilai 76,9 \%, dilihat dari kontrol navigasi dapat berjalan dengan baik, ada 2-3 PC dari 40 PC yang kurang baik ketika menjalankan aplikasi dikarenakan VGA atau RAM kurang memenuhi standart minimal.

3. Dalam aspek Eficiency menyatakan aplikasi Virtual Gallery 3D mendapatkan hasil "sangat baik" dengan total nilai $79,9 \%$, terlihat dari tidak membutuhkan waktu atau delay yang lama ketika menggunakan aplikasi ini, namun ditemukan pula beberapa proses membutuhkan waktu lama dikarenakan performa PC yang kurang dari standar yang dibutuhkan.

4. Dalam aspek Memorablility menyatakan aplikasi ini "baik" dengan nilai 74,2 \%, digunakan untuk memberikan informasi terkait candi Hindu Budha. Hal ini dapat dilihat dari pemggunaan menu dan tampilan yang mempermudah untuk mencari informasi.

5. Terakhir dari data diatas bahwa dalam aspek Satisfaction menyatakan aplikasi Virtual Gallery 3D ini "sangat baik" dengan nilai 85,4 \%, karena permodelan 3D asset dan interior dalam galeri menarik. 


\section{KESIMPULAN DAN SARAN}

Salah satu topik yang menjadi tantangan adalah model media informasi yang sebelumnya di desain konvensional dalam menampilkan informasi terutama bidang sejarah, baik itu keilmuan murni maupun sejarah untuk media pembelajaran. Pengetahuan candi Hindu Budha pada dasarnya merupakan pengetahuan yang sangat menarik dan wajib diketahui oleh semua orang, baik anak anak remaja maupun masyarakat umum, karena sejarah Candi Hindu Budha termasuk bangunan suci peninggalan masa klasik Indonesia yang digunakan sebagai tempat pemujaan oleh umat beragama Hindu maupun Budha. Berdasarkan hasil analisa pengolahan data, diperoleh hasil bahwa dari 5 variabel usability yang digunakan pada kuesioner, hanya 1 variabel yang signifikan digunakan untuk menganalisis usability aplikasi yaitu memorability. Dari 5 variabel tersebut aplikasi virtual gallery 3D memenuhi 4 variabel lainnya sehingga dapat disimpulkan bahwa aplikasi android belum memenuhi kriteria-kriteria Usability, Learnability 85,6 \%, System Performance 76,9 \%, Eficiency 79,9 \%, Memorability 74,2 \%, Satisfaction 85,04\%. diharapkan kedepanya hasil dari penelitian ini mampu menjadi dasar untuk pengembangan media dengan konten yang lebih kompleks sesuai dengan perkembangan zaman.

\section{REFERENSI}

Dedi Rianto (2014), Pengukuran Usability Sistem Menggunakan Use Questionnaire Pada Aplikasi Android. Jurnal Sistem Informasi (JSI), VOL. 6, NO. 1, April 2014.

Iqbal Azmi, Perancangan User Experience Aplikasi Marketplace Paket Wisata Indonesia untuk Wisatawan Lokal. Jurnal Ilmu Komputer Agri Informatika. Volume 5 Nomor 1 halaman $51-60$.

Marini (2013), Efektivitas Penggunaan Metode gallery walk dalam meningkatkan kemampuan siswa Pada Pembelajaran Basa Arab di MTS Al- Fatah Tarakan. Fakultas Sasatra. Unhas.

Berta (2013), Aplikasi 3D viewer mobile dengan menggunakan teknologi Virtual Reality.
Jurnal Teknik Pomits Vol. 2, No. 2, (2013) ISSN: 2337-3539 (2301-9271 Print).

Wisnubro (2018), Lima Elemen Penting Menjawab Tantangan Revolusi Industri 4.0.[online] https://jpp.go.id/teknologi/iptek/315273 lima-elemen-pentingmenjawab tantanganrevolusi-industri-4-0.

AECT (1977). The Definition of Educational Technology. Washington: Association for Educational Communication and Technology.

Kay Staney (2002), Virtual Environment and Technology. Chapter 8. Lawrence Erbaum Acosiates.

Peraturan Pemerintah No. 10 Tahun 1993 tentang Benda Cagar Budaya.

Undang-Undang No 11 Tahun 2010 menjelaskan tentang Pelestarian Cagar Budaya.

Seftiawan, Dhita (2018), Ini 5 Elemen untuk Hadapi Revolusi Industri 4.0. [online] Tersedia: http://www.pikiranrakyat.com/pendidikan/20 18/01/17/ini-5-elemen-untuk-hadapirevolusi-industri-40-418079.

Selfi (2017). Pemodelan 3 Dimensi Candi Wringinlawang Menggunakan Metode Structure From Motion untuk Dokumentasi Cagar Budaya. Jurnal Teknik ITS Vol. 6, No. 2 (2017), 2337-3520 (2301-928X Print).

Ayung Candra Padmasari 